\title{
PEMBUATAN MESIN PELONTAR BOLA (PENBAL) ALAT BANTU PEMBELAJARAN DAN LATIHAN OLAHRAGA BOLAVOLI
}

\author{
Juli Candra ${ }^{1}$, Ahmad Muchlisin Natas Pasaribu' ${ }^{2}$, Ahcmad Fauzan $^{3}$ \\ Fakultas Ilmu Pendidikan, Universitas Bhayangkara Jakarta Raya \\ juli.candra@dsn.ubharajaya.ac.id,ahmad.muchlisin@dsn.ubharajaya.ac.id, \\ ahcmad.fauzan@dsn.ubharajaya.ac.id
}

\begin{abstract}
Abstrak: Seluruh ranah kehidupan manusia pada saat ini tidak terlepaskan dari kemajuan teknologi sehingga berdampak juga pada dunia olahraga dengan memberikan sebuah kontribusi dalam peningkatan prestasi atlet dalam mencapai prestasi puncak yang tidak terlepas dari sarana prasarana yang terus berkembang mengunakan teknologi terbaru yang sangat membantu atlet dalam peningkatan kemampuan fisik, teknik, taktik dan mental. Teknologi mampu membuat atlet lebih mandiri dalam melaksanakan latihan sehingga kemapuan indifidu serta potensi yang dimiliki dalam penguasaan suatu cabang olahraga dapat dikembangkan dengan baik sampai pada penguasaan teknik yang baik dan benar dalam kemampuan teknik otomatisasi gerakan. Di dalam pelaksanaan penelitian ini peneliti telah membuat sebuat terobosan dalam teknologi terhadap pengembanggan teknik olahraga bola voli, pada teknik smash. Peneliti membuat sebuah mesin pelontar bola yang dinamakan dengan Penbal. Alat ini mampu meningkatkan kemampuan teknik smash pada atlet bola voli. Melalui metode penelitian R \& D yang dikembangkan oleh Borg dan Gall, peneliti mampu menciptakan sebuah alat bantu latihan yang efektif dan efisien dalam peningkatan kemampuan teknik atlet bola voli supaya dapat melakukan latihan smash secara mandiri dalam memperbaiki teknik smash yang lebih baik.
\end{abstract}

Kata Kunci : Penbal, Latihan Bola Voli

\begin{abstract}
The whole realm of human life at this time is inseparable from technological advancements so that it also impacts on the world of sports by making a contribution in increasing athlete achievement in achieving top achievements that cannot be separated from infrastructure that continues to develop using the latest technology that greatly helps athletes in improving physical abilities, technique, tactics and mentality. Technology is able to make athletes more independent in carrying out training so that the individual abilities and potential possessed in mastering a sport can be well developed to the mastery of good and correct techniques in the ability to automate movement techniques. In carrying out this study, researchers have made a breakthrough in technology for the development of volleyball sports techniques, in the smash technique. Researchers make a ball throwing machine that is treated with (Penbal). This tool is able to improve the ability of smash techniques in volleyball athletes. By using the $R \& D$ research method developed by Borg and Gall, researchers were able to create an effective and efficient training tool in increasing the ability of volleyball athletes to be able to do special smash training independently in improving better smash techniques.
\end{abstract}

Keywords: Penbal, Volleyball Training

\section{PENDAHULUAN}

Berdasarkan hasil observasi peneliti dibeberapa sekolah dan klub bola voli di kota Bekasi dalam pelaksanaan pembelajaran dan latihan untuk cabang olahraga bola voli dalam penguasaan teknik yang baik dan benar sangat kurang sekali dimiliki oleh siswa, sehingga hasil yang diperoleh dari pelaksanaan teknik dari cabang olahraga bola voli tidak sesuai dengan yang diharapkan sehingga berdampak terhadap prestasi yang diperoleh. Melihat kondisi tersebut, peneliti berupaya mencari apa yang menjadi kendala bagi para atlet terutama saat melakukan teknik smash. Peneliti melihat kurangya afektifitas gerakan yang dilakukan oleh atlet sehingga saat melakukan smes bolanya sering keluar lapangan, tersangkut di net serta penempatan bolanya tidak efektif dan efisien. Untuk melakukan teknik smash 
atlet harus memiliki patner yang baik untuk melambungkan bola supaya bola dapat dipukul dengan baik.

Untuk memperoleh teknik yang baik seorang atlet harus latihan secara kontiniu dan melakukan gerakan tersebut secara berulang ulang sehingga akan mendapatkan otomatisasi gerakan, sehingga dalam pelaksanaan teknik saat bertanding akan memperoleh poin. Namun yang menjadi kendala dalam latihan bola voli terutama teknik smash kurangya patner bagi atlet saat melakukan latihan mandiri. Melihat kondisi seperti ini timbul ide bagi peneliti untuk menciptakan suatu alat yang dapat digunakan untuk membantu latihan dan pembelajaran dalam permainan bola voli terutama untuk teknik smash. Alat ini diharapkan supaya atlet mampu latihan mandiri tanpa harus adanya patner yang membantu untuk melambungakan bola. Melihat beberapa permasalahan diatas peneliti akan menbuat mesin pelontar bola, yang peneliti beri nama Penbal.

Melihat perkembangan teknologi yang begitu pesat, peneliti berupaya membuat sebuah mesin yang akan membantu atlet dalam pelaksanaan latihan terutama untuk cabang olahraga bola voli. Mesin yang dibuat merupakan mesin pelontar bola yang akan membantu atlet dalam melaksanakan latihan sehingga akan meningkatkan performa atlet dalam menghadapi pertandingan. Mesin pelontar bola yang akan diciptakan akan sanggat membantu dalam peningkatan kualitas dari teknik masing - masing atlet karena tanpa adanya patner atlet akan bisa latihan secara mandiri seperti pada bola voli, saat melakukan smes atlet membutuhkan patner untuk melambungkan bola supaya atlet bisa melakukan smes namun dengan mesin pelontar. Atlet tidak perlu adanya patner tetapi akan dibantu oleh mesin pelontar untuk melambungkan bola.

Penelitian ini bertujuan untuk membuat sebuah mesin pelontar yang akan membantu dalam proses latihan bola voli, mesin ini akan membantu atlet untuk dapat melakukan latihan secara mandiri tanpa harus ada patner sebagai pelambung bola. Kemudian bagi pelatih dapat diberikan kemudahan dalam pelaksanan program latihan dalam meningkatkan performa atlet.

\section{Permainan Bola Voli}

Permainan bolavoli diciptakan pada tahun 1895 oleh William G. Morgan, yaitu seorang pembina pendidikan jasmani di YMCA (Young Christian Association) di Kota Holy Yoke, Massachusetts, Amerika Serikat. W.G. Morgan menciptakan permainan di udara dengan cara pukul memukul, melewati jaring yang dibentangkan dengan lapangan yang sama luasnya. Bola yang digunakan saat itu adalah mengambil dari bagian dalam bolabasket dan jaring (net) yang digunakan adalah jaring untuk main tenis. Pada mulanya permainan ini diberi nama Minonette. Kemudian atas saran dari Dr. Halsted
Springfield namanya diganti menjadi Volleyball yang artinya memvoli bola secara bergantian (Yunus, 1992:2). Adapun lapangan permainan bolavoli menurut PB. PBVSI dalam Bachtiar (2010: 20-25) adalah : Lapangan permainan berbentuk persegi panjang dengan ukuran $18 \times 9 \mathrm{~m}$, dikelilingi oleh daerah bebas yang luas minimum di semua sisi $3 \mathrm{~m}$. Daerah bebas permainan adalah ruang di atas daerah permainan yang bebas dari segala halangan. Daerah permainan harus memiliki ketinggian minimum $7 \mathrm{~m}$ dari permukaan lapangan. Sedangkan untuk pertandingan resmi FIVB, daerah bebas harus berukuran minimum $5 \mathrm{~m}$ dari garis samping dan $8 \mathrm{~m}$ akhir. Daerah bebas permainan harus memiliki ketinggian minimum 12,5 m dari permukaan lapangan. Menurut Bachtiar (1999:7), ide dasar permainan bolavoli itu adalah memasukkan bola ke daerah lawan melewati suatu rintangan berupa tali atau net. Kemudian untuk memenangkan (memainkan) bola di udara sebelum bola jatuh atau bola menyentuh lantai. Sesuai dari ide permainan bolavoli, agar dapat bermain bolavoli dengan baik, seorang pemain harus dapat menguasai teknik dasar permainan bolavoli. Adapun teknik dasar permainan bolavoli menurut Asep (2008:35-39) terdiri dari beberapa bagian, diantaranya yaitu servis (service), passing, smash (spike), membendung bola (block).

\section{Tehnik Smash}

Smash merupakan suatu teknik dalam permainan bolavoli yang sangat dibutuhkan dalam olahraga bolavoli, yang berguna untuk melakukan serangan. Hal ini sesuai pendapat Yunus (1990) yang menyatakan "Smash adalah pukulan yang utama dalam penyerangan dalam usaha mencapai kemenangan". Keterangan ini menjelaskan bahwa smash merupakan komponen teknik penting dalam bolavoli tim untuk menyerang. Dikarenakan pentingnya smash, setiap klub berusaha mencari pemain yang bertubuh tinggi dan mempunyai lompatan yang tinggi agar klub itu dapat memenangkan pertandingan. Hal ini juga didukung oleh pendapat Bachtiar (2010) yang mengemukakan bahwa "Smash adalah pukulan yang utama dalam melakukan penyerangan ke daerah lawan". Teknik dalam melakukan smash menurut Syafrudin (2014) secara umum yakni: 1) langkah awal, 2) tolakan atau take off untuk melompat, 3) Memukul bola saat melayang di udara, 4) mendarat kembali setelah memukul bola.

Untuk melakukan smash yang baik, atlet harus mampu melakukan keempat fase tersebut di atas secara harmonis. Kesalahan yang dilakukan pada sah satu fase gerakan akan mengakibatkan gangguan pada proses smash yang dilakukan, yang akibatnya tidak sempurnanya smash yang dilakukan. Untuk lebih jelasnya proses pelaksanaan smash seperti yang telah dijelaskan di atas, dapat dilihat pada gambar berikut: 


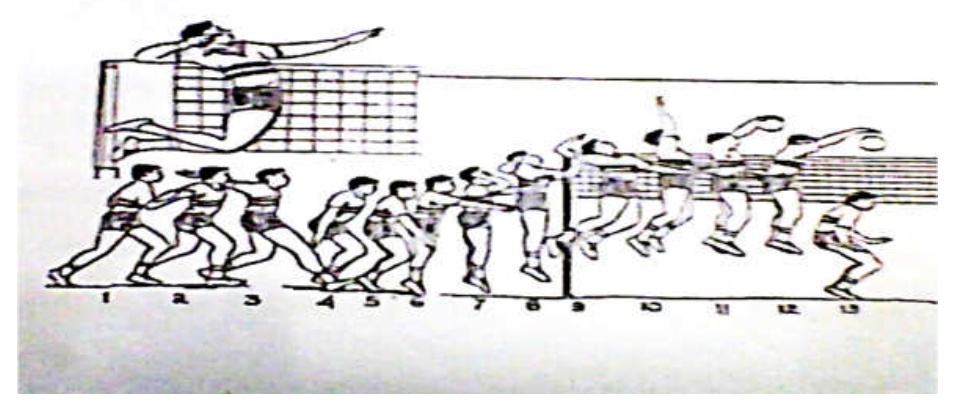

Gambar 1. Rangkaian Gerakan Smash

Gambar diatas memberikan penjelasan bahwa smash harus dimulai dengan awalan yang baik. Sesudah itu atlet harus melakukan tolakan (take off) dengan benar. Kemudian atlet harus mampu memukul bola pada saat bola melayang di udara pada posisi ketinggian yang ideal, agar ia dapat melewati block lawan dan mengarahkan bola ke daerah yang kosong, terakhir atlet harus mampu mendarat dengan keseimbangan yang baik, dan tidak boleh menyentuh net, yang akan mengakibatkan poin untuk lawan, dengan melakukan singkronisasi gerakan dari tahap awal sampai tahap akhir akan melahirkan smash yang akurat. Alat pelontar bola yang akan peneliti buat nantiknya akan mampu memperbaiki teknik smes atlet untuk menjadi lebih baik karena atlet dapat melakukan latihanya secara berulang - ulang dengan bantuan mesin pelontar bola tanpa harus dibantu patner untuk melambungkan bola, sehingga masing masing atlet bola voli dapat melakukan latihan secara mandiri dengan bantuan mesin pelontar bola dan akan meningkatkan kemampuan atlet menjadi lebih baik dalam menghadapi setiap pertandingan.

\section{Mesin Pelontar Bola}

Alas ini berukuran 1 x $0,5 \mathrm{M}$, yang berfungsi sebagai alas dari mesin pelontar bola, alas ini akan

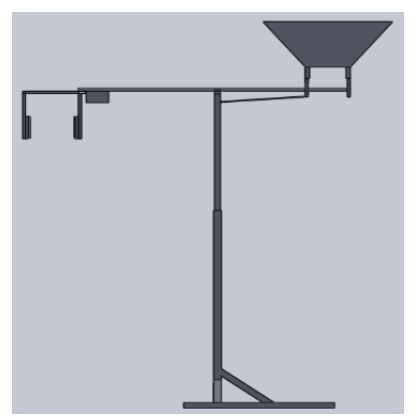

(a) Tampilan Sisi Depan dilengkapi dengan 4 buah roda yang akan memudahkan atlet untuk memindahkanya, kemudian dilengkapi dengan tiang penyangga dengan panjang 3 $M$ yang bisa di stel secara otomatis yang terbuat dari besi hallow dengan diameter 5 x $5 \mathrm{~cm}$ dengan ketebalan $3 \mathrm{~mm}$.

Bagian atas dari alat pelontar bola merupakan rangkayan yang di pasang mesin pelontar dan alat untuk tempat bergulirnya bola voli. Alat ini dilengkapi oleh 2 buah besi pipa dengan panjang $2 \mathrm{~m}$. Di ujung mesin terpasang mesin yang akan membantu untuk melontarakan bola voli yang bisa di atur kearah mana yang di inginkan oleh atlet agar bola mampu di smash diatas net. Kemudian bagian atas dari mesin ini juga dilengkapi oleh dua buah alat penjepit bola yang nantinya juga bisa digunakan sebagai alat penggangi mesin secara manual yang juga bisa digunakan untuk latihan smash dan melatih teknik servis atas.

Adapun wadah penyimpanan bola sebelun digulirkan kearah mesin pelontar. Wadah ini terbuat dari besi nako dengan ukuran 40 x $30 \mathrm{~cm}$, kemudian setiap sisi wadah ini dilapisi oleh kain panel yang anti air supaya bolanya bisa dikumpulkan sebelun digulirkan.

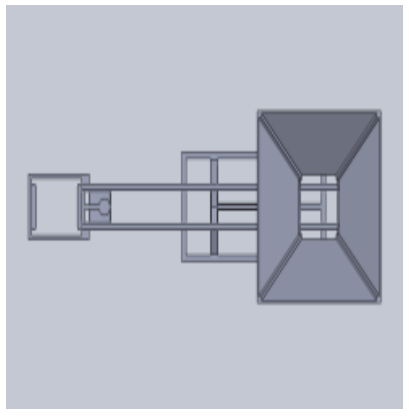

(b) Tampilan Sisi Atas 


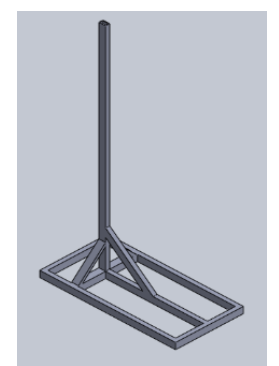

(c) Alas

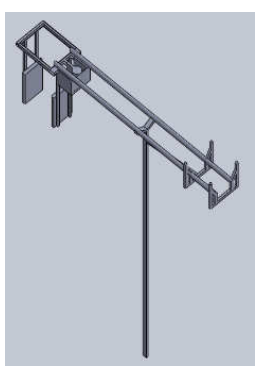

(d) Bagian atas

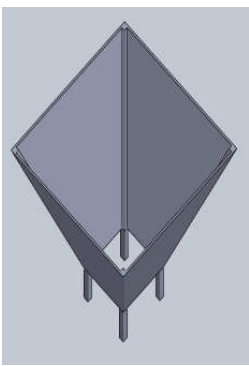

(e) Wadah Bola

Gambar 2. Desain Mesin Pelontar Bola Voli

Cara kerja mesin pelontar awalnya bola dimasukan kedalam corong, menurut analisa peneliti alat ini setiap kali bekerja mampu melontarkan 10 buah bola voli secara bergantian. Lontaran dari mesin tersebut mampu diarakan diatas net sesuat dengan situasi pertandingan dalam permainan olahraga bola voli.

\section{METODE}

Penelitian dilaksanakan pada laboratorium teknik dan lapanggan bola voli Universitas Bhayangkara Jakarta Raya pada bulan maret September 2019 dengan jumlah atlet yang melakukan uji coba untuk efektifitas alat bantu teknik smes sebanyak 15 orang atlet bola voli. Penelitian ini mengunakan metode penelitian pengembangan atau lebih dikenal metode $\mathrm{R} \& \mathrm{D}$. Metode penelitian dan pengembangan merupakan suatu metode penelitian yang digunakan untuk menghasilkan produk dan mampu menguji keefektifan produk tersebut (Sugiyono, 2012).

Peneliti menciptakan sebuah mesin pelontar yang akan membantu atlet dalam proses latihan bola voli. Adapun langkah - langkah penelitian $\mathrm{R}$ \& D menurut sugiyono :1)research \& information collecting, 2)planning, 3)develop Preliminary of product, 4)preliminary field testing, 5)main product revision, 6)main field testing, 7) operational product revision, 8)operasional field testing, 9) final product revision, 10) dissemination and implementation.
Untuk melihat hasil dari kemampuan gerak teknik smash bola voli peneliti mengunakan tim ahli untuk menganalisis kemampuan teknik smash yang dimiliki atlet serta dari hasil tes akan terlihat sejauh mana kemanfaatan alat Penbal dalam meningkatkan kemampuan teknik smash bola voli.

\section{HASIL DAN PEMBAHASAN}

Berdasarkan hasil sketsa awal yang dibuat oleh tim peneliti maka dihasilkan sebuah media untuk alat bantu atlet dalam melakukan latihan yaitu:

1) Alat bantu latihan dengan mengunakan tenaga mesin

Alat bantu ini mengunakan dua tenaga mesin dinamo dan dua inferter untuk mengatur frekuensi kecepatan mesin, yang mampu melontarkan bola voli, sehingga dapat membantu atlet untuk melakukan teknik smash tanpa harus mengunakan toser untuk melambungkan bola

\section{2) Alat bantu manual tanpa mengunakan tenaga} mesin

Alat ini didisain tanpa mengunakan mesin tetapi mampu melatih atlet untuk melakukan teknik smash, alat ini mampu menyesuaikan tingkat kebutuhan atlet dalam melakukan latihan supaya teknik yang dihasilkan menjadi lebih baik. 


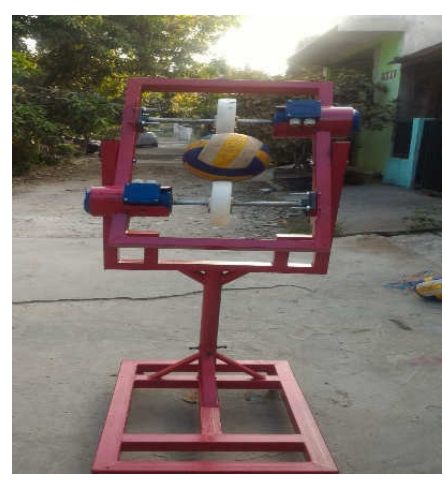

(a) Pakai Tenaga Mesin

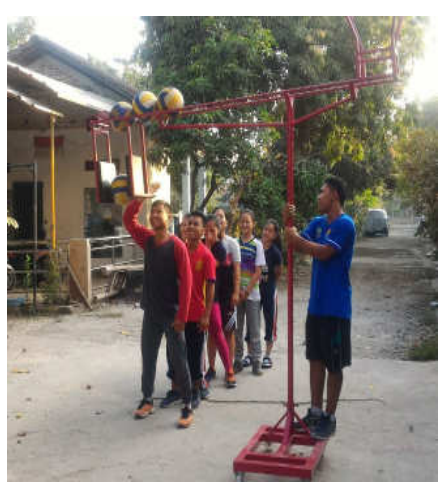

(b) Tanpa Mesin

Gambar 3. Alat Bantu Latihan Bola Voli

Tabel 1. Hasil Tes Awal Teknik Smash Sebelum Mengunakan Alat Bantu Pelontar Bola (Pembal)

\begin{tabular}{|c|c|c|c|c|c|c|c|}
\hline \multirow{2}{*}{ No } & \multirow{2}{*}{ Nama atlet } & \multicolumn{2}{|c|}{ Fase awal } & \multicolumn{2}{c|}{ Fase utama } & \multicolumn{2}{c|}{ Fase akhir } \\
\cline { 3 - 8 } & & Skor & Nilai & Skor & Nilai & Skor & Nilai \\
\hline 1 & APG & 31 & 65 & 40 & 38 & 37 & 46 \\
\hline 2 & AZP & 28 & 58 & 36 & 36 & 35 & 44 \\
\hline 3 & AAZ & 31 & 65 & 49 & 38 & 43 & 54 \\
\hline 4 & AFL & 36 & 75 & 45 & 42 & 51 & 64 \\
\hline 5 & ARK & 26 & 54 & 36 & 39 & 38 & 48 \\
\hline 6 & CK & 35 & 73 & 43 & 33 & 40 & 50 \\
\hline 7 & GCY & 24 & 50 & 35 & 38 & 38 & 48 \\
\hline 8 & KAT & 33 & 69 & 38 & 43 & 36 & 45 \\
\hline 9 & KWP & 37 & 77 & 41 & 34 & 41 & 51 \\
\hline 10 & MFR & 37 & 77 & 36 & 37 & 50 & 63 \\
\hline 11 & MHY & 32 & 67 & 50 & 33 & 39 & 49 \\
\hline 12 & MZP & 27 & 56 & 38 & 36 & 43 & 54 \\
\hline 13 & MFZ & 30 & 63 & 44 & 44 & 38 & 48 \\
\hline 14 & MY & 38 & 79 & 52 & 38 & 51 & 64 \\
\hline 15 & MIR & 31 & 65 & 42 & 33 & 42 & 53 \\
\hline & Rata -rata & 31,7 & 66,2 & 41,6 & 37,4 & 41,4 & 52,6 \\
\hline & & & & & & & \\
\hline
\end{tabular}

Upaya untuk melihat sejauh mana hasil penelitian, peneliti dan tim ahli melakukan tes awal sebelum melakukan latihan mengunakan alat bantu pelontar bola (Penbal) untuk mengetahui kemampuan teknik smes yang dimiliki atlet bola voli universitas bhayangkara Jakarta raya. Berdasarkan tabel 1 distribusi tes awal pada kemapuan teknik smash atlet sebelum menggunakan alat pembal rata rata hasilnya 51,90. Hasil ini menggambarkan bahwa kemampuan yang dimiliki atlet masih rendah.

Kemudian peneliti membuat sebuah terobosan berupa alat bantu latihan smash yang dapat digunakan oleh atlet dalam peningkatan kemampuan teknik serta dapat menunjang atlet dapat melakukan latihan secara mandiri, sehingga mempercepat atlet dalam penguasaan teknik untuk lebih baik. Dari hasil beberapa kali eksperimen terciptalah sebuah alat bantu latihan smash yang diberinama Penbal.

Setelah alat bantu terangkai maka peneliti melakukan serangkaian tes untuk melihat sejauh mana keefektifan pembal dalam peningkatan teknik smash. Kegiatan ini tidak terlepas dari peranan ahli teknik mesin dan ahli teknik bola voli dalam menyempurnakan mesin pelontar bola voli penbal 
untuk teknik smash. Setelah alat penbal diangap efektif oleh tim ahli maka peneliti melakukan latihan teknik smash mengunakan alat pembal. Setelah melakukan delapan kali pertemuan peneliti melakukan tes terhadap atlet sejauh mana hasil yang diperoleh terhadap kemampuan teknik smash mengunakan alat bantu.

Tabel 2. Hasil Tes Smash Kedua Setelah Mengunakan Alat Bantu Pelontar Bola (Penbal)

\begin{tabular}{|c|c|c|c|c|c|c|c|}
\hline \multirow{2}{*}{ No } & \multirow{2}{*}{ Nama siswa } & \multicolumn{2}{|c|}{ Fase awal } & \multicolumn{2}{c|}{ Fase utama } & \multicolumn{2}{c|}{ Fase akhir } \\
\cline { 2 - 8 } & & Scor & Nilai & scor & Nilai & Scor & Nilai \\
\hline 1 & APG & 38 & 79 & 50 & 64 & 55 & 69 \\
\hline 2 & AZP & 45 & 94 & 60 & 77 & 61 & 76 \\
\hline 3 & AAZ & 36 & 75 & 53 & 68 & 53 & 66 \\
\hline 4 & AFL & 40 & 83 & 49 & 63 & 43 & 54 \\
\hline 5 & ARK & 34 & 71 & 40 & 51 & 41 & 51 \\
\hline 6 & CK & 40 & 83 & 64 & 82 & 63 & 79 \\
\hline 7 & GCY & 36 & 75 & 44 & 56 & 50 & 63 \\
\hline 8 & KAT & 33 & 69 & 42 & 54 & 47 & 59 \\
\hline 9 & KWP & 37 & 77 & 50 & 64 & 52 & 65 \\
\hline 10 & MFR & 39 & 81 & 54 & 69 & 56 & 70 \\
\hline 11 & MHY & 40 & 83 & 66 & 85 & 65 & 81 \\
\hline 12 & MZP & 36 & 75 & 43 & 55 & 45 & 56 \\
\hline 13 & MFZ & 42 & 88 & 63 & 81 & 54 & 68 \\
\hline 14 & MY & 38 & 79 & 52 & 67 & 57 & 71 \\
\hline 15 & MIR & 39 & 81 & 55 & 71 & 53 & 66 \\
\hline & Rata - rata & 38,2 & 79,5 & 52,3 & 67,1 & 53 & 66,2 \\
\hline
\end{tabular}

Tabel 3. Hasil Tes Smash Ketiga Setelah Mengunakan Alat Bantu Pelontar Bola Voli (Penbal)

\begin{tabular}{|c|c|c|c|c|c|c|c|}
\hline \multirow{2}{*}{ No } & \multirow{2}{*}{ Nama siswa } & \multicolumn{2}{|c|}{ Fase awal } & \multicolumn{2}{c|}{ Fase utama } & \multicolumn{2}{c|}{ Fase akhir } \\
\cline { 3 - 8 } & & Scor & Nilai & Scor & Nilai & Scor & Nilai \\
\hline 1 & APG & 42 & 88 & 63 & 81 & 71 & 89 \\
\hline 2 & AZP & 45 & 94 & 70 & 90 & 73 & 91 \\
\hline 3 & AAZ & 44 & 92 & 73 & 94 & 64 & 80 \\
\hline 4 & AFL & 39 & 81 & 60 & 77 & 60 & 75 \\
\hline 5 & ARK & 42 & 88 & 75 & 96 & 72 & 90 \\
\hline 6 & CK & 43 & 90 & 62 & 79 & 63 & 79 \\
\hline 7 & GCY & 46 & 96 & 72 & 92 & 75 & 94 \\
\hline 8 & KAT & 42 & 88 & 61 & 78 & 65 & 81 \\
\hline 9 & KWP & 40 & 83 & 64 & 82 & 72 & 90 \\
\hline 10 & MFR & 45 & 94 & 70 & 90 & 71 & 89 \\
\hline 11 & MHY & 43 & 90 & 60 & 77 & 62 & 78 \\
\hline 12 & MZP & 44 & 92 & 63 & 81 & 73 & 91 \\
\hline 13 & MFZ & 41 & 85 & 64 & 82 & 62 & 78 \\
\hline 14 & MY & 46 & 96 & 73 & 94 & 76 & 95 \\
\hline 15 & MIR & 43 & 90 & 61 & 78 & 60 & 75 \\
\hline & Rata - rata & 43 & 89,8 & 66,06 & 84,73 & 67,93 & 85 \\
\hline
\end{tabular}

Berdasarkan hasil dari tabel 2 distribusi tes kedua dengan mengunakan alat bantu pelontar bola voli penbal pada kemampuan teknik smash atlet rata rata hasilnya $70,97 \%$. Dari hasil yang diperoleh 
terdapat peningkatan kemapuan teknik smes yang dimiliki oleh atlet UBHARA JAYA dari tes awal sebelum mengunakan penbal, bahkan sampai pada tes ke dua telah mengunakan mesin pelontar bola persentase peningkatanya $19,07 \%$ selama delapan kali pertemuan. Supaya hasil penelitian lebih akurat diatas $80 \%$ peneliti melakukan latihan kepada atlet agar hasil yang diperoleh dalam mengunakan penbal dapat lebih dirasakan. Sebelum mengambil tes ketiga peneliti melakukan latihan selama delapan kali pertemuan untuk melihat sejauh mana hasil yang diperoleh oleh atlet dalam melakukan teknik smash.

Berdasarkan hasil kemampuan teknik yang dilakukan oleh tim ahli setelah mengunakan alat bantu latihan yaitu mengunakan mesin pelontar bola penbal dapat di lihat pada tabel 3 persentasi peningkatan teknik smash setelah dilakukan penilayan analisis gerak yaitu $86,51 \%$. Berdasarkan hasil tersebut peneliti menyimpulkan bahwa alat bantu latihan penbal mampu meningkatkan kemampuan smash atlet bola voli unversitas Bhayangkara Jakarta raya.

\section{KESIMPULAN}

Dari hasil pengembanggan sebuah teknologi peneliti dan tim ahli telah menyelesaikan sebuah alat bantu dalam latihan bola voli yaitu pada teknik smes yang diberi dengan nama Penbal. Latihan dengan mengunakan Penbal mampu membantu atlet bola voli untuk mengembangkan teknik smash dengan baik, walaupun pada awalnya latihan smash atlet harus menunggu rekan untuk melambungkan bola tetapi sekarang dengan menggunakan alat ini (penbal) atlet mampu latihan secara mandiri untuk mengembangkan kemampuan teknik smash. Ujicoba dilapangan peneliti dan tim ahli melihat efektifitas media yang digunakan mencapai diatas 80 persen. Melihat hasil tersebut peneliti dan tim ahli dapat menyimpulkan bahwa latihan mengunakan media penbal mampu mengembangkan dan meningkatkan kemampuan atlet bola voli pada teknik smash.

\section{REFERENSI}

Bompa, Tudor O., Haff, G.Gregory. 2009. Periodization. Theory and Methodology of Training. Fifth Edition. Champaign: Human Kinetics

Asep, Rohadi. 2008. Metode Latihan dan Pembelajaran Bola Voli.Yogjakarta: Alfabeta

Bachtiar. 2010. Pengetahuan Dasar Permainan Bolavoli. Padang: DIP Proyek UNP.

Hadi, Sutrisno, 1990. Statistik Jilid II, Fakultas Psycologi UGM, Yogyakarta.

Nurhasan.2001.Tes dan Pengukuran dalam Pendidikan Jasmani. Jakarta: Diknas bekerjasama dengan Dirjen Olahraga.

Sugiono. 2012. Metode Penelitian Kualitatif dan $R \& D$. Bandung: Alfabeta.

Syafruddin. 2014. Permainan Bola Voli. TrainingTeknik-Taktik. Padang: FIK UNP

Yunus, M. 1992. Olahraga Pilihan Bolavoli. Jakarta: Depdikbud. 